\title{
The relationships between nomophobia, alexithymia and metacognitive problems in an adolescent population
}

\author{
Mesut Yavuz, ${ }^{1,2}$ Beyza Altan², Büşra Bayrak², Merve Gündüz², Nurullah Bolat ${ }^{3}$ \\ ${ }^{1}$ French LapeHospital, Child and Adolescent Psychiatry Istanbul; ${ }^{2}$ Department of Psychology, Istanbul Aydin University, \\ İstanbul; ${ }^{3}$ Department of Child and Adolescent Psychiatry, Çanakkale Onsekiz Mart University School of Medicine, \\ Çanakkale, Turkey. E-mail: mesutyavuzdr@gmail.com \\ Received: 5th July 2018, Revised: 11th July 2018, Accepted: 11th July 2018
}

SUMMARY: Yavuz M, Altan B, Bayrak B, Gündüz M, Bolat N. The relationships between nomophobia, alexithymia and metacognitive problems in an adolescent population. Turk J Pediatr 2019; 61: 345-351.

\begin{abstract}
Nomophobia refers to an intense anxiety and stress caused by being out of contact with mobile phones (MPs). It is known that excessive engagement with MPs decreases adolescents' psychological well-being, social and academic functioning. The aim of this study was to investigate the associations of nomophobia with alexithymia which is characterized by difficulties in describing and expressing emotions and using empathy, and with the metacognition characteristics which have the function of controlling the cognitions in an adolescent population. The study was conducted on 1817 participants ( $\mathrm{n}=972,54 \%$ female, $\mathrm{n}=835,46 \%$ male). The Nomophobia Questionnaire (NMP-Q), The Twenty-Item Toronto Alexithymia Scale (TAS-20) and The Metacognition Questionnaire for Children and Adolescents (MCQ-C) were administered to participants. A question form for socio-demographic data was also administered to participants and their families. Cathegorical variables were analyzed by chi-square test, and numerical variables were analyzed by independent sample $t$ test. The relationships between the scales' scores were analyzed by the Pearson-product moments correlation test. The predictive effects of alexithymia, metacognition problems and gender were assessed by multiple linear regression analysis. Nomophobia, alexithymia and metacognition problem levels were significantly higher in females than males. There was a significant correlation between NMP-Q and TAS-20 scores and MCQ-C scores. TAS-20, MCQ-C scores and gender significantly predicted the nomophobia when NMP-Q score was a dependent variable. Therapeutic interventions for improving social skills like emphatic thinking and/or increasing emotional expression may be beneficial in the treatment of adolescents with alexithymic traits which experience nomophobia. Moreover, interventions that enhance metacognitive skills which can control negative thoughts triggered by the possibility of losing contact with MPs may increase treatment success.
\end{abstract}

Key words: nomophobia, adolescent, alexithymia, metacognition.

Nowadays, mobile phones (MPs) have diffused into many areas of our lives, and become an integral part of our lives due to their many functions. MPs are mainly used for accessing information, participating in social networks, increasing social interactions, planning and organizing work, access to e-mails, shopping and playing games. ${ }^{1}$ Besides their occupational and social benefits, excessive use of MPs may lead to psycho-social problems such as irritability, increased anxiety level, depressive symptoms, social withdrawal and decreased academic and occupational success. ${ }^{1}$

Nomophobia is described as an intense discomfort and anxiety caused by being out of contact with MPs. Loss of contact with MPs can easily increase the level of anxiety in some 
individuals, since it may also mean difficulty in reaching family members, friends and health services while confronting with an emergency situation. ${ }^{2}$ The prevalence of nomophonia is reported as $42 \%$ in Turkish college students ${ }^{3}$ and $73 \%$ in Turkish high school students. ${ }^{4}$ The research conducted on the general population in the UK revealed that the frequency of nomophobia was $\% 53.5$

Metacognition may be an important factor for nomophobia as well as many psychiatric and addiction problems. Metacognition is defined as a skill that provides observation and control over thoughts and has the function of correcting cognitive distortions. ${ }^{6}$ It was revealed that low metacognitive skills may increase anxiety levels, ${ }^{6}$ addiction problems ${ }^{7}$ and decrease self-esteem levels. ${ }^{8}$ Low selfesteem levels, ${ }^{9}$ and anxiety disorders such as panic disorder ${ }^{10}$ and social phobia ${ }^{11}$ have been reported to increase the risk of nomophobia.

When it is taken into consideration that social isolation increases MP addiction, ${ }^{12}$ alexithymia may be associated with problematic use of MPs and nomophobia. Alexithymia is defined as a personality structure that is characterized by inability to recognize and verbalize emotions, difficulty in using empathy and excessive externally-oriented thinking. ${ }^{13}$ Individuals with alexithymia experience significant problems in interpersonal relationships and social interaction due to the inabilities in recognizing emotions and empathizing. ${ }^{14,15} \mathrm{It}$ was reported that social isolation that is seen in individuals with alexithymia may increase the risk of technology and internet addiction. ${ }^{16}$ We suggest that these type of deficits may also trigger the problem of overuse of MPs. Additionally, it was reported that impulsivity increases the likelihood of overuse of the $\mathrm{MPs}^{17}$ and impulsive behaviors can be seen frequently in alexithymic individuals. ${ }^{18}$

In light of this data we hypothesized that participants with alexithymia characteristics and high metacognitive problems would have increased risk of nomophobia. In order to test this hypothesis, the aim of this study was to investigate the association between alexitymia levels, metacognitive problems and the development of nomophobia in a group of Turkish adolescents.

\section{Method}

\section{Procedure and Participants}

One thousand eight hundred and seventeen participants ( $\mathrm{n}=97254 \%$ female, $\mathrm{n}=835$ $46 \%$ male) studying in six different high schools (two in Istanbul and four in Samsun) and aged between 14 and 17 were included in this cross-sectional study. The mean age of the participants was 15.42 (SD: 1.12) for females and 15.42 (SD: 1.08) for males. The study was conducted in two separate provinces (Istanbul and Samsun) in order to increase the sample size and reduce the effect of regional differences on the results. The high schools were selected according to the permissions obtained from Istanbul and Samsun Provincial Directorates of National Education. Random sampling method was used to include participants in the study. Participants fulfilled the scales under the supervision of a researcher in their classrooms. According to the information received from the families, adolescents with intellectual disability or a neurodevelopmental disorder, with a history of psychopharmacologic and/or psychotherapeutic treatment, with a history of chronic medical disease and with poor literacy were excluded from the study. The aim of the present study and procedure were explained in detail to the participants and their families and verbal and written informed consents were taken. The study was approved the by Clinical Research Ethics Committee (Issue: 29/08/2017-55253).

\section{Instruments}

Socio-demographic Data Form: The adolescents and their parents were asked to fulfill the socio-demographic data form in order to get information about participants' age, gender, class, school, income status of the families, medical and psychotherapeutic history.

The Nomophobia Questionnaire (NMP-Q): The NMP-Q was developed by Yildirim and Correia $^{19}$ to measure nomophobia. The NMP-Q has 20 items, and all items are rated using a 7 -point Likert scale ranging from 1 (strongly disagree) to 7 (strongly agree). The scores obtained from the scale can be between 20 and 140. Scores $\leq 20$ indicate absence of nomophobia. Scores between 21 and 59, 
between 60 and 99, and $\geq 100$ indicate mild, moderate and severe nomophobia; respectively. The scale has four dimensions: (1) not being able to access information, (2) not being able to communicate, (3) losing connectedness and (4) giving up convenience. The Cronbach alpha value of the Turkish scale was 0.92 , and its four factors were $0.94,0.90,0.74$, and 0.91 , respectively. ${ }^{3}$

The Twenty-Item Toronto Alexithymia Scale (TAS-20): TAS-20 is a self-report scale was developed by Bagby et al. ${ }^{20,21}$ to measure the dimensions of alexithymia. All items are rated using a 5-point Likert scale ranging from 1 (strongly disagree) to 5 (strongly agree). TAS20 has three sub-scales: (TAS-1) difficulty in identifying feelings, (TAS-2) difficulty in describing feelings, (TAS-3) externallyoriented thinking. The scores obtained from the scale can be between 20 and 100 . The scores $\geq 59$ on indicate alexithymia. The validity and reliability study of the Turkish version of TAS-20 was conducted by Gulec et al. ${ }^{22}$ For adolescents $\geq 15$ years old, the Cronbach alpha value for the scale was 0.85 , and the Cronbach alpha values of the three sub-scales were 0.85 , 0.77 and 0.55 , respectively. It was reported the psychometric properties of Turkish TAS-20 were acceptable for this age group. ${ }^{16}$

The Metacognition Questionnaire for Children and Adolescents (MCQ-C): MCQ-C consists of 24 items rated using a 4-point Likert scale ranging from one to four. It has four factors; (1) positive beliefs about worry, (2) negative beliefs about worry, (3) superstitious, punishment and responsibility beliefs and (4) cognitive monitoring. ${ }^{23}$ The Cronbach alpha value of Turkish MCQ-C was $0.73 .{ }^{24}$ The scores obtained from the scale range from 24 to 96 . The high scores on the scale indicate high metacognitive errors.

\section{Statistical Analysis}

The data were analyzed by using SPSS 23 programme for Windows. Kolmogorov smirnov test revealed that the data was normally distributed $(p>0.05)$. Frequency and mean values were calculated. Categorical variables were analyzed by chi-square test and numerical variables were analyzed by independent sample $t$ test. A preliminary power analysis was performed in order to evaluate the required sample size, and type-I and type-II errors were accepted at 0.05 and $20 \%$ levels, respectively. Pearson-product moments correlation test was used to analyze the correlations between the scores of scales. The predictive effects of gender, and the MCQ-C and TAS-20 scores were assessed by multivariate linear regression analysis. The cronbach's alpha values were calculated for all scales for internal consistency. Statistical significance level was accepted at $\mathrm{p}<0.05$ and $\mathrm{p}<0.001$.

\section{Results}

A total of 1867 adolescents, 997 female and 870 male, were included in the study. Twentytwo of the participants, who stated that they do not use MPs, were excluded from the study. Twenty-eight, of the participants who did not fulfill the scales properly were not included in the statistical analysis. As a result, statistical analyzes were performed on 1817 participants ( $\mathrm{n}=97254 \%$ female, $\mathrm{n}=83546 \%$ male). Preliminary power analysis indicated that, the minimum required number of both male and female groups was 552, and our sample size was acceptable for statistical analysis. The mean age of the participants was 15.42 (SD: 1.12) for females and 15.42 (SD: 1.08) for males. The Cronbach's alpha values for NMP-Q, TAS-20 and MCQ-C were, 0.810, 0.727 , and 0.755 ; respectively. The Cronbach's alpha values indicated acceptable internal consistency for all scales.

According to the scores on NMP-Q the rates of severe, moderate and mild nomophobia were $14 \%(n=133) \% 50(n=489)$ and $\% 35$ $(n=347)$ in females. These ratios in males were found as $10 \%(n=84), 44 \%(n=367)$ and $45 \%$ ( $n=383)$, respectively. A total of 4 participants ( 3 females and 1 male; both $<\% 1$ ), were found to be "no nomophobic". Nomophobia, alexithymia and metacognitive problems were significantly higher in females than males $(p<0.001)$. Statistical comparison of NMP-Q, TAS-20, MCQ-C scores of females and males is presented in Table I.

There was a weak correlation between NMP-Q and TAS-20 $(r=0.227)$, a moderate correlation 
Table I. The Comparison of NMP-Q, TAS-20, MCQ-C Scores Between Males and Females.

\begin{tabular}{|c|c|c|c|c|c|}
\hline Scales & Gender & Mean & SD & $\mathrm{t}$ & $\mathrm{p}$ \\
\hline \multirow[t]{2}{*}{ NMP-Q } & Female & 70.52 & 25.22 & & $<0.001$ \\
\hline & Male & 64.23 & 25.28 & 2.554 & \\
\hline \multirow[t]{2}{*}{ TAS-20 } & Female & 54.21 & 9.55 & & 0.011 \\
\hline & Male & 53.09 & 9.32 & 7.151 & \\
\hline \multirow[t]{2}{*}{ TAS-20 Factor 1} & Female & 18.73 & 6.90 & & $<0.001$ \\
\hline & Male & 16.54 & 6.53 & 2,693 & \\
\hline \multirow[t]{2}{*}{ TAS-20 Factor 2} & Female & 13.56 & 3.20 & & 0.007 \\
\hline & Male & 13.16 & 3.28 & $-7,968$ & \\
\hline \multirow[t]{2}{*}{ TAS-20 Factor 3} & Female & 21.92 & 3.95 & & $<0.001$ \\
\hline & Male & 23.40 & 4.04 & 6,409 & \\
\hline \multirow[t]{2}{*}{ MCQ-C } & Female & 61.43 & 10.75 & & $<0.001$ \\
\hline & Male & 57.74 & 11.53 & 7.151 & \\
\hline \multirow[t]{2}{*}{ MCQ-C Factor 1} & Female & 11.90 & 4.09 & & $<0.001$ \\
\hline & Male & 12.34 & 4.19 & 10.227 & \\
\hline \multirow[t]{2}{*}{ MCQ-C Factor 2} & Female & 16.61 & 4.55 & & $<0.001$ \\
\hline & Male & 14.46 & 4.49 & 6.266 & \\
\hline \multirow[t]{2}{*}{ MCQ-C Factor 3} & Female & 15.50 & 4.24 & & $<0.001$ \\
\hline & Male & 14.23 & 4.45 & 6.245 & \\
\hline \multirow[t]{2}{*}{ MCQ-C Factor 4} & Female & 17.42 & 3.93 & & $<0.001$ \\
\hline & Male & 16.70 & 4.07 & 7.018 & \\
\hline
\end{tabular}

Independent Sample t Test; SD: Stadard Deviation, NMP-Q: The Nomophobia Questionnaire,

TAS-20: The Twenty- Item Toronto Alexithymia Scale, MCQ-C: The Metacognition Questionnaire for Children and Adolescents

Table II. The Correlation Coefficients Between NMP-Q, TAS-20 and MCQ-C Scores.

\begin{tabular}{llll}
\hline & NMP-Q & TAS-20 & MCQ-C \\
\hline NMP-Q & 1 & $0.227^{* *}$ & $0.318^{* *}$ \\
TAS-20 & $0.227^{* *}$ & 1 & $0.383^{* *}$ \\
MCQ-C & $0.318^{* *}$ & $0.383^{* *}$ & 1 \\
\hline
\end{tabular}

Pearson-product Moment Correlation Test; NMP-Q: The Nomophobia Questionnaire,

TAS-20: The Twenty- Item Toronto Alexithymia Scale, MCQ-C: The Metacognition Questionnaire for Children and Adolescents; ${ }^{* *} \mathrm{p}<0.001$

between NMP-Q and MCQ-C ( $\mathrm{r}=0.318)$, a moderate correlation between TAS-20 and MCQ-C ( $\mathrm{r}=0.383)$ ( $\mathrm{p}<0.001)$. Correlation analysis results were presented in Table II.

Alexithymia levels, metacognitive problems, and gender significantly predicted the nomophobia when NMP-Q score was a dependent variable $(p<0.001)$. The results of the regression analysis is presented in Table III.

\section{Discussion}

This study was conducted on 1817 high school students studying in İstanbul and Samsun. Our results showed that metacognitive problems and alexithymia characteristics were associated with nomophobia. In addition, rate of nomophobia was significantly higher in females than males. Although there has been an increasing interest in nomophobia 
Table III. Multivariate Linear Regression Analysis in Which NMP-Q Scores are Considered as the Dependent Variable.

\begin{tabular}{|c|c|c|c|c|c|c|c|}
\hline $\begin{array}{l}\text { Independent } \\
\text { variables }\end{array}$ & $\mathrm{R}^{2}$ & Adjusted $\mathrm{R}^{2}$ & B & $\beta$ & $\mathrm{t}$ & 95 \% CI Lower-Upper & $\mathrm{p}$ \\
\hline & 0.405 & 0.403 & & & & & \\
\hline Constant & & & 23.800 & & 5.521 & $16.15-32.96$ & $<0.001$ \\
\hline MCQ-C & & & 0.483 & .214 & 8.79 & $.376-.590$ & $<0.001$ \\
\hline TAS-20 & & & 0.388 & .140 & 5.978 & $.249-.502$ & $<0.001$ \\
\hline Gender & & & -4.109 & -.08 & -3.608 & $-6.31,-1.87$ & $<0.001$ \\
\hline
\end{tabular}

NMP-Q: The Nomophobia Questionnaire, TAS-20: The Twenty- Item Toronto Alexithymia Scale, MCQ-C: The Metacognition Questionnaire for Children and Adolescents; CI: Confidence Interval, $\beta$ : Standardized Coefficients

in the literature, the number of studies still remains limited. In previous studies it was reported that metacognitive problems ${ }^{25}$ and alexithymia characteristics ${ }^{26,16}$ were related to internet and technology addiction. To the best of our knowledge, this study is the first to focus on the relationship between alexithymia, metacognitive problems and nomophobia. Considering that the problem of nomophobia in adolescents is more frequent than in other age groups, ${ }^{9}$ we suggest that the results of this study may give significant contributions to the literature.

Alexithymia is a characteristic related to individuals' inabilities in identifying and expressing emotions and weak skills in using empathy. ${ }^{27,14}$ Because of such issues, individuals with alexithymia may experience significant problems in social interaction. ${ }^{16}$ It should be taken into consideration that adolescents use MPs frequently for social interaction. For adolescents with alexithymic characteristics, involving in social interaction behind a screen can be a less anxious way than face-to-face communication. Therefore, being out of MP contact may lead to intense anxiety and stress in adolescents with alexithymia due to poor social skills. In addition, the relationship between alexithymia and impulsivity has been reported. ${ }^{28,29}$ Individuals with impulsive personality may use technological devices like MPs for entertainment purposes such as playing games, watching movies, listening to music for pleasure. ${ }^{30,17}$ Our results indicate that alexithymia increase the risk of nomophobia development in adolescents. This may be due to the tendency of getting pleasure from MPs and difficulty of controlling the time spent with MPs, because of increased impulsivity in alexithymic adolescents.

Metacognition manages the cognitive system and emotions related to the cognitions. ${ }^{31}$ Good metacognitive skills have protective effects on anxiety disorders, ${ }^{32}$ and behavioral addictions. ${ }^{7}$ When individuals lose contact with MPs, they can have certain thoughts like "I will lose my contact with my friends", "My boredom will not stop if I can not reach my mobile phone", "In a situation of an illness or emergency, I will not be able to reach my family or friends", "I will lose my connection to the internet, I will not be able to reach the information I need and lose control concerning my assignments.". These automatic thoughts may increase the anxiety and stress levels. Since good metacognitive skills allow the ability to control and correct cognitive errors, they can also provide the management of anxiety and stress caused by these thoughts. Poor metacognitive skills can trigger the development of nomophobia because the individuals may not be able to regulate their anxiety and stress related to automatic thoughts about losing contact with MPs.

Our results indicate that gender significantly predict nomophobia and nomophobia levels are higher in female adolescents than males. The research conducted on college students in Turkey revealed that severity of nomophobia was higher in females compared to males. ${ }^{3}$ Our research was conducted on high school students, and our results are consistent with the results of the study done by Yildirim et al. ${ }^{3}$ This result may be related to the widespread use of MPs for social communication purposes. 
It was shown that females are more likely to use MPs with the purpose of social interaction than males. ${ }^{33}$

In conclusion, the results of the study indicate that alexithymia levels and metacognitive characteristics are related to the development of nomophobia in adolescents. Because of the social skill problems in alexithymia, adolescents with this problem may prefer to use MPs for social interaction. Moreover, the alexithymics may not have control over the time spent on the MP due to their impulsive characteristics. Thus, alexithymia may increase the risk of nomophobia. Metacognitive problems may contribute to the development of nomophobia due to the problem of regulating cognitive errors that arise from losing contact with MPs. In the adolescents who problematically use MPs and experience nomophobia, a detailed examination of cognitive processes related to this issue, and therapeutic interventions which aim to improve the metacognitive skills may increase the therapeutic success. Additionally, attempts for improving the social skills and the ability of emotional expression and using empathy in adolescents with alexithymic personality traits may prevent the nomophobia development.

The cross-sectional nature of our study limits our ability to evaluate the causality and effect. Longitudinal studies may help to better understand the influence of alexithymia and metacognitive errors on the nomophobia development. The reliability and validity study of the NMP-Q has been conducted on college students. The psychometric properties of the NMP-Q have not been investigated for adolescents under 17 years old. This is a limitation of this study. The strength of our study is the sample size. This study has the largest sample size when compared to the previous research in the international literature about the associations between nomophobia and mental health among adolescent population. Additionally, it should be kept in mind that this study is the first one that examines the relationship between nomophobia, alexithymia and metacognition skills, and we suggest that the results of this study will guide other researchers for further studies.

\section{REFERENCES}

1. Park N, Kim YC, Shon HY, Shim H. Factors influencing smartphone use and dependency in South Korea. Comput Human Behav 2013; 29: 1763-1770.

2. King ALS, Valença AM, Nardi AE. Nomophobia: The mobile phone in panic disorder with agoraphobia: Reducing phobias or worsening of dependence? Cogn Behav Neurol 2010; 23: 52-54.

3. Yildirim C, Sumuer E, Adnan M, Yildirim S. A growing fear: Prevalence of nomophobia among Turkish college students. Inform Dev 2016; 32: 13221331.

4. Gezgin DM, Çakır Ö. Analysis of nomopfobic behaviors of adolescents regarding various factors. J Hum Sci 2016; 13: 2504-2519.

5. SecurEnvoy. $66 \%$ of the population suffer from Nomophobia the fear of being without their phone. Available from: https://www.securenvoy.com/en-gb/ blog/66-population-suffer-nomophobia-fear-beingwithout-their-phone/ (Last Accessed on 15.06. 2018.)

6. Yilmaz AE, Gençöz T, Wells A. The temporal precedence of metacognition in the development of anxiety and depression symptoms in the context of life-stress: A prospective study. J Anxiety Disord 2011; 25: 389-396.

7. Spada MM, Caselli G, Nikčević AV, Wells A. Metacognition in addictive behaviors. Addict Behav 2015; 44: 9-15.

8. Kleitman S, Stankov L. Self-confidence and metacognitive processes. Learn Individ Differ 2007; 17: 161-173.

9. Argumosa-Villar L, Boada-Grau J, Vigil-Colet A. Exploratory investigation of theoretical predictors of nomophobia using the Mobile Phone Involvement Questionnaire (MPIQ). J Adolesc 2017; 56: 127-135.

10. King ALS, Valença AM, Silva ACO, Sancassiani F, Machado S, Nardi AE. "Nomophobia": Impact of cell phone use interfering with symptoms and emotions of individuals with panic disorder compared with a control group. Clin Pract Epidemiol Ment Health 2014; 10: 28-35.

11. King ALS, Valença AM, Silva ACO, Baczynski T, Carvalho MR, Nardi AE. Nomophobia: Dependency on virtual environments or social phobia? Comput Human Behav 2013; 29: 140-144.

12. Bian $M$, Leung L. Linking loneliness, shyness, smartphone addiction symptoms, and patterns of smartphone use to social capital. Soc Sci Comput Rev 2015; 33: 61-79.

13. Nemiah JC, Freyberger H, Sifneos PE. Alexithymia: A view of the psychosomatic process. In: Hill OW, (ed). Modern Trends in Psychosomatic Medicine. London: Butterworths, 1976: 430-439. 
14. Grynberg D, Luminet O, Corneille O, Grezes J, Berthoz S. Alexithymia in the interpersonal domain: A general deficit of empathy? Pers Individ Dif 2010; 49: 845-850.

15. Feldmanhall O, Dalgleish T, Mobbs D. Alexithymia decreases altruism in real social decisions. Cortex 2013; 49: 899-904.

16. Bolat N, Yavuz M, Eliaçık K, Zorlu A. The relationships between problematic internet use, alexithymia levels and attachment characteristics in a sample of adolescents in a high school, Turkey. Psychol Health Med 2017; 23: 604-611.

17. Billieux J, Van der Linden M, Rochat L. The role of impulsivity in actual and problematic use of the mobile phone. Appl Cogn Psychol 2008; 22: 11951210

18. Velotti P, Garofalo C, Petrocchi C, Cavallo F, Popolo R, Dimaggio G. Alexithymia, emotion dysregulation, impulsivity and aggression: A multiple mediation model. Psychiatry Res 2016; 237: 296-303.

19. Yildirim C, Correia AP. Exploring the dimensions of nomophobia: Development and validation of a selfreported questionnaire. Comput Human Behav 2015; 49: 130-137.

20. Bagby RM, Parker JDA, Taylor GJ. The twenty-item Toronto Alexithymia Scale-I: Item selection and cross-validation of the factor structure. J Psychosom Res 1994; 38: 23-32.

21. Bagby RM, Taylor GJ, Parker JDA. The twentyitem Toronto Alexithymia Scale-II: Convergent, discriminant, and concurrent validity. J Psychosom Res 1994; 38: 33-40.

22. Gulec H, Köse S, Güleç MY, et al. Reliability and factorial validity of the Turkish version of the 20Item Toronto Alexithymia Scale (TAS-20). Bull Clin Psychopharmacol 2009; 19: 214-220.

23. Bacow TL, Pincus DB, Ehrenreich JT, Brody LR. The metacognitions questionnaire for children: Development and validation in a clinical sample of children and adolescents with anxiety disorders. J Anxiety Disord 2009; 23: 727-736.
24. Irak M. Üstbilis ölçeği çocuk ve ergen formunun Türkçe standardizasyonu, kaygı ve obsesif-kompülsif belirtilerle ilişkisi. Türk Psikiyatri Dergisi 2012; 23: 47-54.

25. Spada MM, Langston B, Nikcevic AV, Moneta GB. The role of metacognitions in problematic internet use. Comput Human Behav 2008; 24: 2325-2335.

26. Craparo G. Internet addiction, dissociation, and alexithymia. Procedia Soc Behav Sci 2011; 30: 10511056.

27. Guttman H, Laporte L. Alexithymia, empathy, and psychological symptoms in a family context. Compr Psychiatry 2002; 43: 448-455.

28. Zlotnick C, Shea MT, Pearlstein T, Simpson E, Costello $\mathrm{E}$, Begin A. The relationship between dissociative symptoms, alexithymia, impulsivity, sexual abuse, and self-mutilation. Compr Psychiatry 1996; 37: 1216.

29. Fossati A, Acquarini E, Feeney JA, et al. Alexithymia and attachment insecurities in impulsive aggression. Attach Hum Dev 2009; 11: 165-182.

30. Han S, Kim KJ, Kim JH. Understanding nomophobia: Structural equation modeling and semantic network analysis of smartphone separation anxiety. Cyberpsychol Behav Soc Netw 2017; 20: 419-427.

31. Wells A. Metacognitive Therapy for Anxiety and Depression. New York, London: The Guilford Press, 2009

32. Lønfeldt, NN, Marin CE, Silverman WK, ReinholdtDunne ML, Esbjørn BH. The role of metacognitions in the association between children's perceptions of maternal control and anxiety. J Child Fam Stud 2017; 26: 1398-1408.

33. Gerlich RN, Browning L, Westermann L. The social media affinity scale: Implications for education. Contemp Issues Educ Res 2010; 3: 35-41. 